\title{
Smart Specialisation Strategies for Elevating Integration of Cultural Heritage into Circular Economy
}

\author{
Jermina Stanojev * and Christer Gustafsson
}

Citation: Stanojev, J.; Gustafsson, C. Smart Specialisation Strategies for Elevating Integration of Cultural Heritage into Circular Economy. Sustainability 2021, 13, 3685.

https://doi.org/10.3390/su13073685

Academic Editor: John Carman

Received: 1 February 2021

Accepted: 16 March 2021

Published: 26 March 2021

Publisher's Note: MDPI stays neutral with regard to jurisdictional claims in published maps and institutional affiliations.

Copyright: (c) 2021 by the authors. Licensee MDPI, Basel, Switzerland. This article is an open access article distributed under the terms and conditions of the Creative Commons Attribution (CC BY) license (https:/ / creativecommons.org/licenses/by/ $4.0 /)$.
Department of Art History, Uppsala University, 75236 Uppsala, Sweden; christer.gustafsson@konstvet.uu.se

* Correspondence: jermina.stanojev@konstvet.uu.se; Tel.: +39-388-9016944

\begin{abstract}
The smart specialisation approach is becoming a strategic instrument for identifying regions' opportunities for growth and sustainable development. It is a place-based approach and plays an important role in benchmarking regional competitiveness. To have a smart specialisation strategy has been thought of as a key factor in making a choice for investment. Smart specialisation strategies represent a policy measure to overcome disorganised and weak parallel activities in developed EU countries and offer support to those areas that have research, technological and production capacity to carry out particular activities. Smart specialisation strategies, therefore, follow the socio-economic situation in countries and their integrated technological, institutional and business processes. The EU Member States and regions recognised that supporting a limited number of well-identified priorities for knowledge-based investments and/or clusters could advance, focusing on competitive assets and realistic growth capabilities reinforced by a critical mass of action and entrepreneurial resources. However, the role of culture and cultural heritage has not been significant in these processes. As the policy review revealed that circular economy should be considered as a broader sustainable development strategy, which should also "support Member States and regions to strengthen innovation for the circular economy through smart specialisations", the purpose of this paper is to lay a basis for a new, stronger complementarity between culture, cultural heritage and adaptive reuse practices, and circular economy concepts through smart specialisation strategies.
\end{abstract}

Keywords: circular economy; culture; cultural heritage; smart specialisations; regional development

\section{Introduction}

Circular economy has become linked to cultural heritage-its reuse, conservation, and valorisation. Recent trends have led to the tendencies that many cities, as well as regions, are aiming at becoming "circular" and "smart", while many of them are not acquainted with the concept of "circular economy" nor familiar with policy instruments and tools that would allow and support their cities and regions toward this transition.

As recently reviewed [1], many regional and city cases of "circularity" and notions of circularity are emphasising materials, energy flows, greenhouse gas emissions, material stocks, analysis and material passport, efficient use of resources, waste, Design for Disassembly, etc. However, recently, researchers, as well as networks, have shown an increased interest in cultural heritage as a resource for circularity, circular cities, circular regions and the use of cultural heritage spatial-territorial resources [2].

Despite that, one of the problems in assessing the role of cultural heritage in circularity becomes more complex because there is no substantial and systematic mapping of the state of the integration of cultural heritage in cities' and regions' circularity strategies and, more importantly, specific tools that are implementing circularity on operational policy levels. This raises the issue of how to go with an assessment of impact if a baseline is lacking. To address this, the paper explores circular economy as a broader sustainable development strategy that should also "support Member States and regions to strengthen innovation for the circular economy through smart specialisations" [3], and the paper commits to 
providing an overall analysis and assessment of state of the art on conditions of cities' and regions' specific tools, such as smart specialisations and their priorities, in order to understand main tendencies in regard to cultural heritage and circularity.

\subsection{Primary Concept of Circular Economy}

The importance of the concept of circular economy in various fields is constantly expanding. In the academic field, the rapid growth of peer-reviewed circular economy articles demonstrates this [4]. Many independent expert institutions and major consulting corporations (Accenture (Dublin, Ireland), Deloitte (London, UK), EY (London, UK), McKinsey \& Company (Stockholm, Sweden)) have recently conducted research and have published different reports on the circular economy [4,5]. There is a large volume of published studies devoted to discussing different concepts and definitions of circular economy [4,6-9]. An analysis of 114 definitions of circular economy [4] was conducted as part of a comprehensive and systematic study of various definitions of circular economy.

The generalisability of much-published research on this issue is problematic, as the research showed that this concept of circular economy with such a wide range of influence, adopted by various stakeholders, often applied from different perspectives, can be misinterpreted and misunderstood [10,11]. Although some research [12] points out that "there are various possibilities for defining circular economy", others [13] claim that "there is no commonly accepted definition of circular economy". There is a consensus among social scientists on the attractiveness of the concept. However, evidence suggests that a commonly accepted definition of circular economy does not exist [4]. The disagreement about scientific evidence on circular economy has been pointed out before, stating that "one interesting difference between circular economy and most of the other schools of sustainable thought is that it has largely emerged from legislation rather than from a group of academics who have split from one field and have started a new one" [14].

In addition, the concept of circular economy is now considered to be one of the most thought-provoking concepts [15] among the prominent concepts that also focus on sustainable development, such as the green economy and the green growth concepts $[16,17]$.

\subsection{Circular Economy in EU Regional Policies and Tools}

The generalisability of the policy framework on circular economy issues in EU regional policies is challenging and insufficient for observing other areas that are contributing to the circular economy like social innovations, eco-innovations, sharing economy initiatives, the level of the greening of the main economic sectors, new business models' implementation, eco-design, architectural initiatives [18] recognised in the cutting edge research on circular economy and could also be relevant at regional levels $[9,19,20]$. The European Commission's monitoring frameworks on circular economy did not offer instruments for following the implementation of circular economy concepts and effects at the local and regional level. Therefore, this research shall contribute to setting up a baseline for the monitoring processes at regional levels through smart specialisations.

At the same time, the regional policy is one of the main strengths of the European Union development policy and the EU Cohesion Policy for 2014-2020 was dedicated to the circular economy as, in the policy's investment framework, significant funding was foreseen for circular economy-related innovation, resource efficiency, small and medium-sized enterprises (SMEs) competitiveness, low-carbon investments and waste management [21]. Overall, the main focus of the EU Cohesion Policy funds is greatly in line with the circular economy concepts and principles.

Considering the role of regions in the EU policy as well as the number of funds that are covering circular economy actions, the research also spotlights the regional level of circular economy implementation. Even the first EU action plan for the Circular Economy advocates that waste management should not be the only issue tackled within the concept of circular economy, but that rather should be considered as a broader sustainable development strategy that also should "support Member States and regions to strengthen 
innovation for the circular economy through smart specialisations" [22]. Circular economy is now explicitly put forward in the European Commission's legislative proposals for the 2021-2027 programming period, and the European Commission has adopted a new Circular Economy Action Plan [23]—one of the major strengths of the European Green Deal [24].

\subsection{Smart Specialisations as a Tool of Circular Economy at Regional and City Level}

The smart specialisations approach is getting to be a key instrument for identifying regions' opportunities for growth, development and circular economy. It is a place-based approach and plays a critical function in benchmarking regional competitiveness and attractiveness. To identify a smart specialisation strategy has been understood as a strategic factor in formulating investment choices and playing a role in circular economy chain and process. The EU Member States and regions agreed that supporting a limited number of well-identified priorities for knowledge-based investments and/or clusters could promote focusing on competitive assets and realistic growth capabilities, reinforced by a critical mass of action withing circularity and entrepreneurial resources [1].

The growing relevance of Smart Specialisation can be witnessed within the transformed Cohesion policy for the period of 2014-2020. The proposal for the Multiannual Financial Framework (MFF) 2021-2027, regarding the cohesion policy after 2020, the Smart Specialisation approach shall continue to be very meaningful in the Cohesion policy implementation. The European Green Deal is entitled to employ a new strain to evaluate the significance of the S3 overseeing the 2021-2027 MFF. Once again, smart specialisations are understood as a tool to complement innovation funding and support the whole innovation cycle with the aim to bring solutions to the market at the regional level [23]. Cultural heritage as a sustainable development enabler [25] is, therefore, another powerful reason to build up a bridge between heritage and the smart specialisation strategies [26].

Smart specialisation strategies represent a policy measure to overcome disorganised and weak parallel activities in EU countries and offer support to those areas that have research, technological and production capacity to carry out particular activities toward circular economy. Smart specialisation strategies, therefore, follow the socio-economic situation in countries and their integrated technological, institutional and business processes. The idea of smart specialisation is constituted to ensure the most effective results through rational and strategic spending of public capital and based on the notion that regions cannot achieve everything in science, technology and innovation and, therefore, it is crucial to follow a thoughtful process of prioritisation, concentrating resources in certain domains of expertise based on the needs and available resources of each region toward circularity.

Corresponding to that, numerous studies have shown an amplified relevance in understanding emerging bottlenecks of the implementation of smart specialisation [27-32]. A number of authors have reported key challenges for smart specialisation-type policy methods in general. For example, one factor is that different structures of governance in the European Member States has reached a position in which mandates for RIS3 practices, implementation and strategy accomplishment are allocated to a broadly variable set of spatial levels of governance $[30,33]$. Another example is that some Member States were not in favour of supporting and promoting new bottom-up policy approaches, while, at the same time, other Member States were familiar with that approach and in support of the traditional top-to-bottom planning [29]. This aspect of bottom-up policy approaches is extremely important when it comes to smart specialisations as a tool for circular economy and cultural heritage because it ensures participatory processes on wider spatial-territorial resources. Nevertheless, an additional challenge is that concrete competencies play a role when it comes to evidence-based policymaking, broad-based consultations and the drafting of innovation strategies for circular economy [30]. Therefore, smart specialisations could be seen as a part of an "economy of relationships", and in particular, of an "economy of cooperative relationships". Foray's original model foresees the EDP as something that emerges between relevant actors, in particular, the emerging domains and-in well- 
functioning regional innovation systems - it can and will, in principle, occur without public intervention [34-36], which circularity shall be aiming for.

\subsection{Smart Specialisations and Cultural Heritage Circularity}

Despite the fact that smart specialisations are part of an "economy of cooperative relationships", researchers have not treated recognition of cultural heritage in European regions' and cities' smart specialisation strategies as a specific tool for circularity in much detail. The generalisability of published research on this and closely related issues is tricky. Research on the subject has been mostly restricted to limited comparisons of different regional strategies, but not on an overall review giving a complete picture of the status in Europe. The research to date has tended to focus on local community and case study results rather than policy and empirical results. Therefore, the existing interpretations fail to resolve the contradiction between cultural heritage attractiveness and cultural heritage as a comprehensive part of regional development and circularity in all its economic, scientific and policy aspects. The most of analysis do not apply the same methodology for all European regions collecting data and have only been carried out in a small number of areas, mainly those that participated in Horizon 2020 or similar research programmes (examples of CLIC, ROCK and RURITAGE case studies/pilot areas).

Although extensive research has been carried out on different cultural heritage related topics, such as health, resilient cities, climate changes, international relations, and participatory governance $[1,2,25,37-43]$, studies do not take into account analysis of role and position of cultural heritage in circularity within regional policies, nor do they examine what missing links there are with development. There has been little quantitative analysis of that field, and it is mainly poorly understood. There is no reliable evidence on how much and if European regions are recognising the importance of cultural heritage under their strategies. In addition, no research has been found that surveyed what the exact percentage of such regions is, and the baseline is lacking.

European Commission's “Mapping Innovation Priorities and Specialisation Patterns in Europe" [22] shows that overall, the most commonly cited priority categories are energy, health, food, materials and ICT, and although it claims that the cultural and creative industries are one of the most common RIS3 priority areas in the EU (besides energy, health, information and communication technologies, food, advanced materials, services, tourism, sustainable innovation, advanced manufacturing systems), far too little attention has been paid to survey relation of cultural heritage to the cohesion policy and existing platforms such as Eye@RIS3. Furthermore, although some research has been carried out on cohesion policies and regional policies in general, there is very little scientific understanding of specific priorities, cultural heritage in this case, under the existing framework. Apart from several authors [1,28-30], there is a general lack of research in this field.

The paper will review the research conducted on NUTS regions (NUTS-for the French Nomenclature d'Unités Territoriales Statistiques, for the English Classification of Territorial Units for Statistics) created by the European Union for referencing the administrative divisions of countries and their priorities identified via online tool Eye@RIS3 within the framework of Smart Specialisation strategies as a tool nurturing circularity. It will focus on clarifying the representation of cultural heritage under existing European regional strategies and their priorities under RIS3 and to what extent it can relate to other domains that include cultural heritage as an important part of their priorities and circularity processes. The objective of the paper is to provide a detailed qualitative and quantitate insight into the operating framework based on data available through the platform.

The purpose of the paper is to lay the basis for a new, stronger complementarity between heritage practices and local economic development through smart specialisation strategies as a circular economy instrument, reviewing approaches of different European regions towards smart specialisations linked to cultural heritage and their fully-fledged participation in circularity. The paper aims to overcome a gap in the data reviews regarding this topic and provide the most extensive list of cultural heritage oriented regions and their 
features across cultural heritage and circularity. The main research objectives of the paper are to:

- Analyse and designate the representation of cultural heritage and culture in existing smart specialisation approach as a tool to strengthen innovation for the circular economy in regard to the total number of regions as well as the total number of priorities;

- Map European regions that are recognising cultural heritage and culture as an integrated part of their strategies toward circularity processes;

- Identify the most significant cultural heritage and culture features and workflows that are currently available in different European regions toward circularity processes;

- Offer a comparison in smart specialisation approaches per economic domains, scientific domain and policy objectives (and their respective sub-domains) as an element of circularity;

- Understand current and further possible advancements on the topic of cultural heritage and culture in smart specialisations.

The paper will serve to further target needs and facilitate decision-making of end-users from all backgrounds and level of expertise that are interested in learning and working in the cultural heritage related smart specialisations for circular economy.

\section{Methodology}

The paper is based on quantitative and qualitative research methods using publicly available data from the Smart Specialisation Platform (S3P) and the dedicated online database, Eye@RIS3. The European Commission set up this platform to facilitate gathering data and managing strategy development and implementation of Research and Innovation Strategies for Smart Specialisations (RIS 3), where European regions and countries provide their innovation-related information. The Eye@RIS3 database, a text database, represents a summary of country-specific and region-specific documents on smart specialisation strategies in order to prioritise investments, increase productivity, stimulate knowledge-driven growth and seek out potential partners for collaboration when it comes to circular economy.

This research uses data of 243 NUTS entities in total, covering the EU-28 and their regions, as well as 8 non-EU countries with their 22 non-EU regions (as of 20 June 2018, when the Eye@RIS3 had the last update of information on regional priorities). Those NUTS entities identified 1401 priorities across economic and scientific domains and policy objectives. This represents a relevant, official source of information with a sufficient amount of data for data analysis purposes and for the objectivity of results.

Although the Eye@RIS3 has been created primarily for non-statistical purposes, this research uses available information for data analysis to uncover the significance and representation of cultural heritage and/or culture in smart specialisations strategies as circular economy tools, and to what extent they relate to economic and scientific domains and policy objectives, and their respective subdomains associated with circular economy at the regional level.

The database is structured according to the Eurostat nomenclature of the NUTS regions. Each NUTS entry, country or region consists of priorities as described in their RIS3s, containing a brief description field. These description fields range from very short (sentence or two) to extensive ones covering well-explained activities and goals. Additionally, where available, detailed RIS3s documentation of smart specialisation can be found. The S3/R\&I priorities in Europe are further associated with the economic and scientific domains as well as EU Policy Objectives (three criteria that will be used for all analyses), based on the Eurostat's NACE2 sectorial codes and OECD categories, the Nomenclature for the Analysis and Comparison of Scientific Programmes and Budgets (NABS 2007) and the so-called "Societal Grand Challenges" identified in Horizon2020, as well as the headline policies in the Innovation Union Flagship Initiative, respectively. 
Economic domains based on the Eurostat's NACE2 sectoral codes and OECD categories and used for research are following: (A) agriculture, forestry and fishing; (B) mining and quarrying; (C) manufacturing; (D) electricity, gas, steam and air conditioning supply; (E) water supply, sewerage, waste management and remediation activities; (F) construction; $(\mathrm{G})$ wholesale and retail trade; repair of motor vehicles and motorcycles; $(\mathrm{H})$ transportation and storage; (I) accommodation and food service activities; (J) information and communication; (K) financial and insurance activities; (L) real estate activities; (M) professional, scientific and technical activities; $(\mathrm{N})$ administrative and support service activities; $(\mathrm{O})$ public administration and defence; compulsory social security; $(\mathrm{P})$ education; $(\mathrm{Q})$ human health and social work activities; $(\mathrm{R})$ arts, entertainment and recreation; (S) other service activities; (T) activities of households as employers; (U) activities of extraterritorial organisations and their bodies. Each of these economic domain folds down into more pre-defined economic sub-domains. The research explores each of them, respectively.

Scientific domains based on the nomenclature for the analysis and comparison of scientific programmes and budgets and used for this research are following: (1) exploration and exploitation of the earth; (2) environment; (3) exploration and exploitation of space; (4) transport, telecommunication and other infrastructures; (5) energy; (6) industrial production and technology; (7) health; (8) agriculture; (9) education; (10) culture, recreation, religion and mass media; (11) political and social systems, structures and processes; (12) general advancement of knowledge: R\&D financed from general university funds (GUF); (13) general advancement of knowledge: R\&D financed from other sources than GUF; (14) defence. Each of these scientific domains folds down into more pre-defined scientific sub-domains, and the research explores each of them, respectively.

EU Policy Objectives category is composed of eleven EU-wide policy areas, each with a set of various pre-defined sub-categories: (A) aeronautics and space; (B) blue growth; (C) cultural and creative industries; (D) digital transformation; (E) KETs; (F) nature and biodiversity; $(\mathrm{G})$ public health and security; $(\mathrm{H})$ service innovation; (I) social innovation; (J) sustainable innovation; $(\mathrm{K})$ other.

The methodology consists of three parts: data collection, data processing and analyses, as shown in Figure 1, which contains all steps. The process starts with the data collection from the Eye@RIS3 database. Since this research required custom data analytics, the Smart Specialisation Platform's entire database has been downloaded and further processed in a spreadsheet-step 1. Each list entry of the database consists of regions (NUTS) code, region/country name, description, economic domains, scientific domains, policy objectives, source and date of source using the same structure as the Eye@RIS3. Two lists were produced that would be later used in analysis 2: total number of regions (TNR) and total number of priorities (TNP) - steps 2 and 3, respectively. These lists contain a total number of NUTS-243 entries in TNR and a total number of priorities 1401 entities in TNP. Furthermore, TNP contains a total number of the domains/categories and their sub-categories.

The process continues with 2 levels of keyword search, performed within the description column (as described in their RIS3s, description columns contain a brief description of priorities - these description fields range from very short (a sentence or two) to extensive ones covering well-explained activities and goals) in the spreadsheet. The 1st level search and the most restrictive one used the "cultural heritage" keywords in the exact order-step 4. After identifying database entries that contain keywords in their descriptive fields, the database was filtered, and a new list is created: cultural heritage priorities (CHP) - step 5. Since some NUTS have more than one priority that contained keywords, a new list-cultural heritage regions (CHR) — was created by filtering CHP to remove duplicated NUTS-step 6. Therefore, CHR is a subset of CHP and contains a smaller number of entries. 


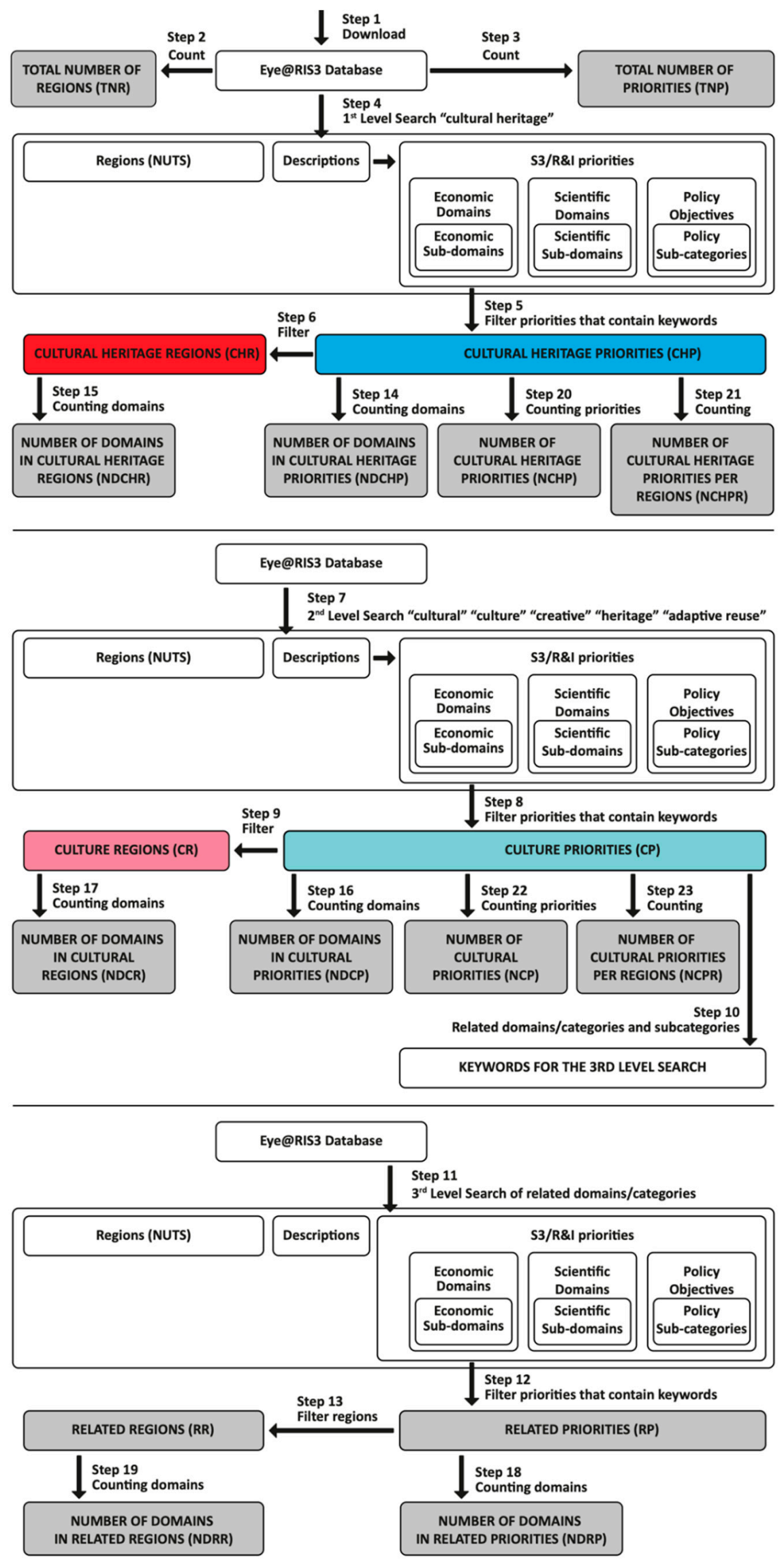

Figure 1. Graphic representation of the methodology. 
Since the database showed inconsistency in using "cultural heritage" across priorities, the 2nd level search was introduced. It was less rigorous as it included a mix of keywords "cultural", "culture", "creative", "heritage", and "adaptive reuse" to select database entries that contain at least one of the keywords at least once-step 7. Similarly to steps 5 and 6, steps 8 and 9 also produced a filtered list based on keywords: culture priorities (CP) and culture regions (CR), respectively. Since the 2 nd level search was less restrictive, $C P$ and $\mathrm{CR}$ contain more entries than $\mathrm{CHP}$ and $\mathrm{CHR}$, respectively.

This implies that only the 1 st level search shows a specific representation of "cultural heritage" in regions' and cities' priorities toward circular economy, while the 2nd level search includes a broader and extended field of "culture" and "cultural heritage".

Furthermore, for the purpose of analysis 1, the 3rd level search was performed on the main database. Keywords used in this search are extracted from CP domains/categories, and sub-categories field as those ones are related to the cultural heritage in a broader sense-step 10. Therefore, this time, the search was not performed on the description field but on the domain/categories field-step 11. Again, similarly to steps 5 and 6, and steps 8 and 9, steps 12 and 13 produced two lists: related priorities (RP) and related regions (RR), respectively.

For the purposes of analyses 1 and 2, further data processing was performed to compress the data and produce lists that the present number of occurrences of specific domains/categories and sub-categories in those lists. Steps 14, 16 and 18 perform this procedure on lists of priorities: number of domains in cultural heritage priorities (NDCHP), number of domains in culture priorities (NDCP), and number of domains in related priorities (NDRP), respectively. Steps 15, 17 and 19 perform this procedure on lists of regions: number of domains in cultural heritage regions (NDCHR), number of domains in culture regions (NDCR) and number of domains in related regions (NDRR), respectively. In those lists, every domain/category and sub-category is assigned with the number of occurrences in the respected list.

For the purposes of analysis 3, four more lists were created. Instead of counting domains/categories and sub-categories, these lists were produced by counting priorities and regions for the first two searches. Therefore, counting the number of priorities in CHP provided number of cultural heritage priorities (NCHP) — step 20, while step 21 provided number of cultural heritage priorities per region (NCHPR). Similarly, counting the number of cultural priorities in CP provided the number of cultural priorities (NCP) - step 22, while step 23 provided the number of cultural priorities per region (NCPR). In this way, all data was prepared, so the analyses could be performed.

\subsection{Analyses}

In order to estimate the importance of the cultural heritage for the circular economy of specific regions and in Europe, three analyses were performed. Each of the three analyses contributes to the designation of the representation of cultural heritage and culture in existing smart specialisations, as well as mapping European regions that are recognising cultural heritage and culture as an integrated part of their strategies. In particular, the first and second analyses offer insight into the most significant cultural heritage and culture features and workflows that are currently available in different European regions. Furthermore, these two analyses offer a comparison in smart specialisation approaches per economic domains, scientific domain and policy objectives and their respective subdomains. The third analysis represents a geospatial map to identify the regional importance of cultural heritage in a restrictive and broader sense.

\subsubsection{Analysis 1}

Analysis 1, as shown in Figure 2, presents the impact of cultural heritage within domains/categories and sub-domains/sub-categories that were related to priorities that recognised cultural heritage in their description. In this way, only relevant and related domains and objectives, including their sub-levels, are analysed. Since two searches 
were used-the restrictive and the broad, with each producing two lists, the priorities and regions-analysis 1 presents the importance of cultural heritage in respect to priorities and regions through four different metrics. The first metric shows a percentage of $\mathrm{CHP}$ in RP by using the following formula: NDCHP/NDRP $\times 100$. The second metric shows a percentage of $\mathrm{CP}$ in RP by using the following formula: NDCP/NDRP $\times 100$. The third metric shows a percentage of CHR in RR by using the following formula: NDCHR/NDRR $\times 100$. The fourth metric shows a percentage of CR in RR by using the following formula: NDCR/NDRR $\times 100$.

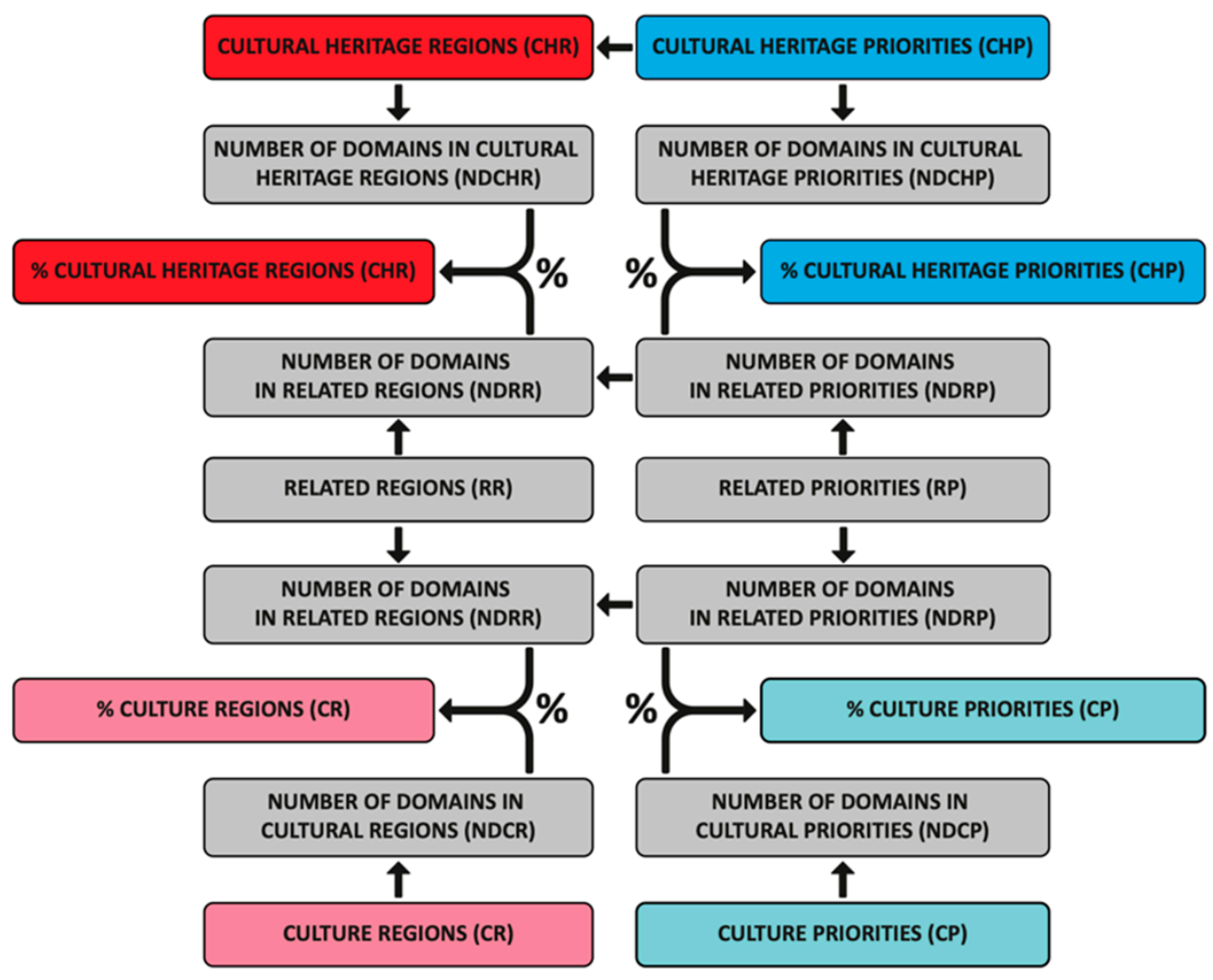

Figure 2. Graphic representation of Analysis 1.

\subsubsection{Analysis 2}

Analysis 2, as shown in Figure 3, follows the same principle as analysis 1, but instead of considering only related domains/categories and sub-categories, it compared them to the total number of domains/categories and sub-categories from steps 2 and 3: TNR and TNP, respectively. Entries containing sub-categories that were not included in the 3rd level search were omitted as they would produce 0 percentages. Therefore, the procedure for obtaining four metrics is the same as in analysis 1, but instead of NDRP and NDRR, lists were divided by TNP and TNR, respectively. This analysis is much broader than the first analysis as many other domains and objectives are included in the total number that has no or very limited relation to cultural heritage. Therefore, percentages in the four metrics are much smaller than in analysis 1.

\subsubsection{Analysis 3}

Analysis 3, as shown in Figure 4, aims to demonstrate the importance of the cultural heritage for each specific region/country (NUTS entity) by expressing percentages of priorities per region that included keywords, without considering domains/categories and sub-domains/sub-categories. Analysis firstly identified the number of priorities containing keywords from 1st search: NCHP and NCHPR, and 2nd level search: NCP and NCPR. Division of these two pair of groups with the following formulas: NCHP/NCHPR $\times 100$ 
and NCP $/$ NCPR $\times 100$ provided results expressed in percentages. Results are presented in the form of a geospatial map and colour coded according to results. Results are expressed in percentages, divided into bins of $10 \%$ for percentages up to $50 \%$ and one bin for all the percentages above $50 \%$.

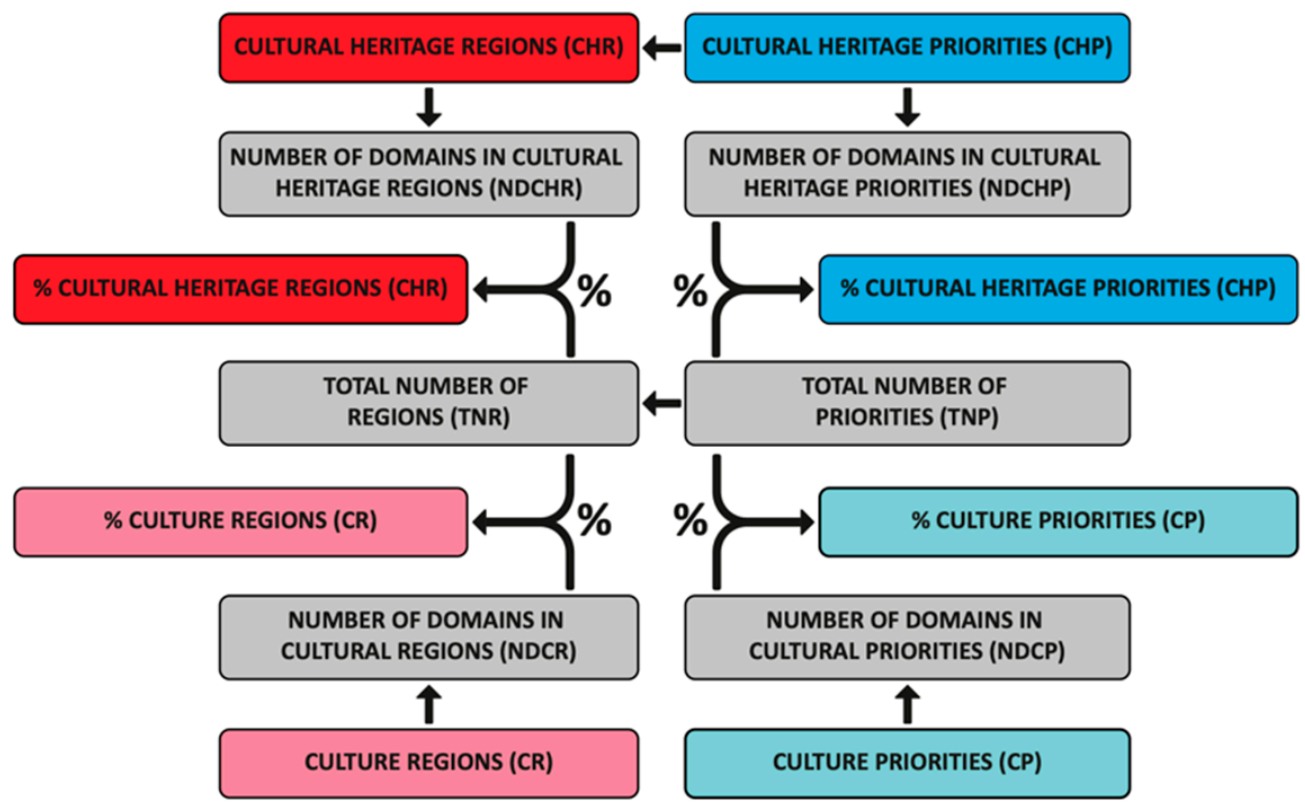

Figure 3. Graphic representation of Analysis 2.

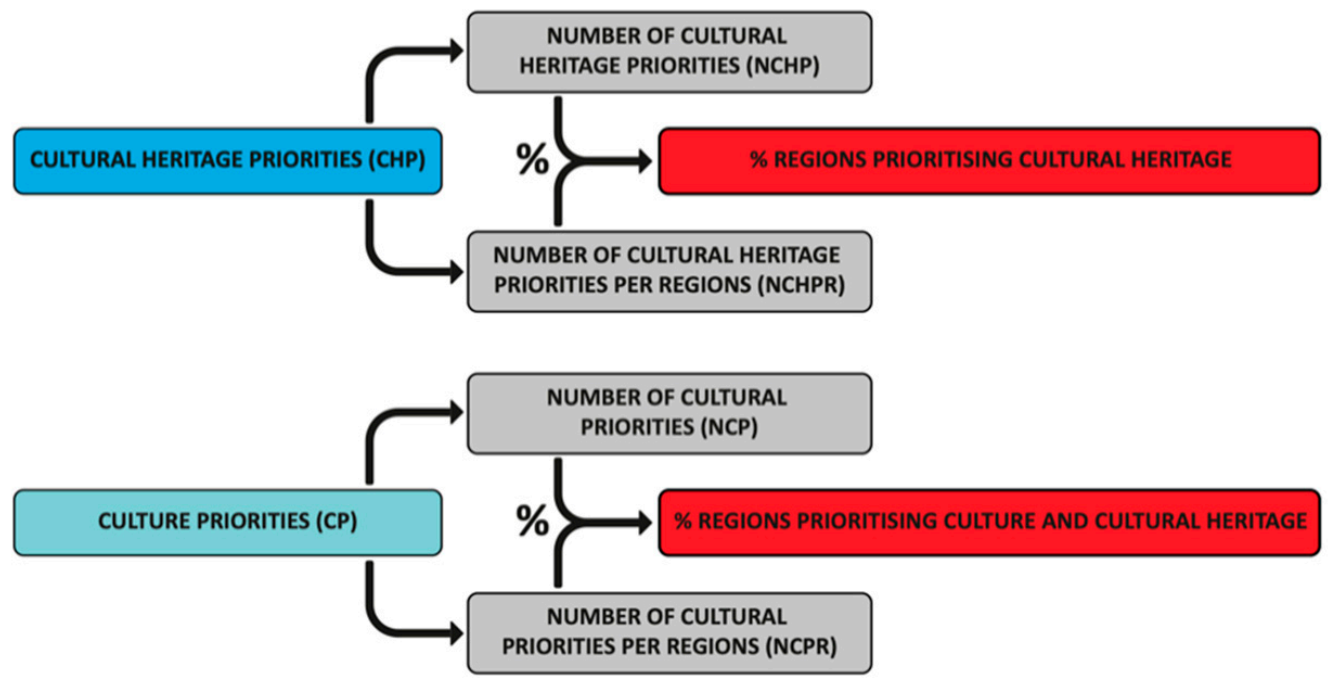

Figure 4. Graphic representation of Analysis 3.

Potentially restraining features of conducted searches can be found in a fact that some extent of regions/countries (NUTS entities) have included either very basic descriptions, did not explicitly mention either one of the search keywords used, even if they should have done so, or simply did not perceive cultural heritage as an asset for their priorities and circular economy.

\section{Results}

\subsection{Analysis 1 Results}

The first set of analyses examined the impact and inclusions of cultural heritage and culture and their direct relation to the three main categories: economic and scientific domains, as well as policy objectives of regions and cities toward circular economy. In this 
way, it was possible to quantify the importance of cultural heritage and culture for each of the categories and sub-categories. Results of Analysis 1, shown in Figure 5, contains only main category items. As expected, this analysis shows the clear linkage of wider aspects of culture and cultural heritage with economic domain $\mathrm{R}$-arts, entertainment and recreation, scientific domain 10-Culture, recreation and mass media, as well as with policy objective C-cultural and creative industries.

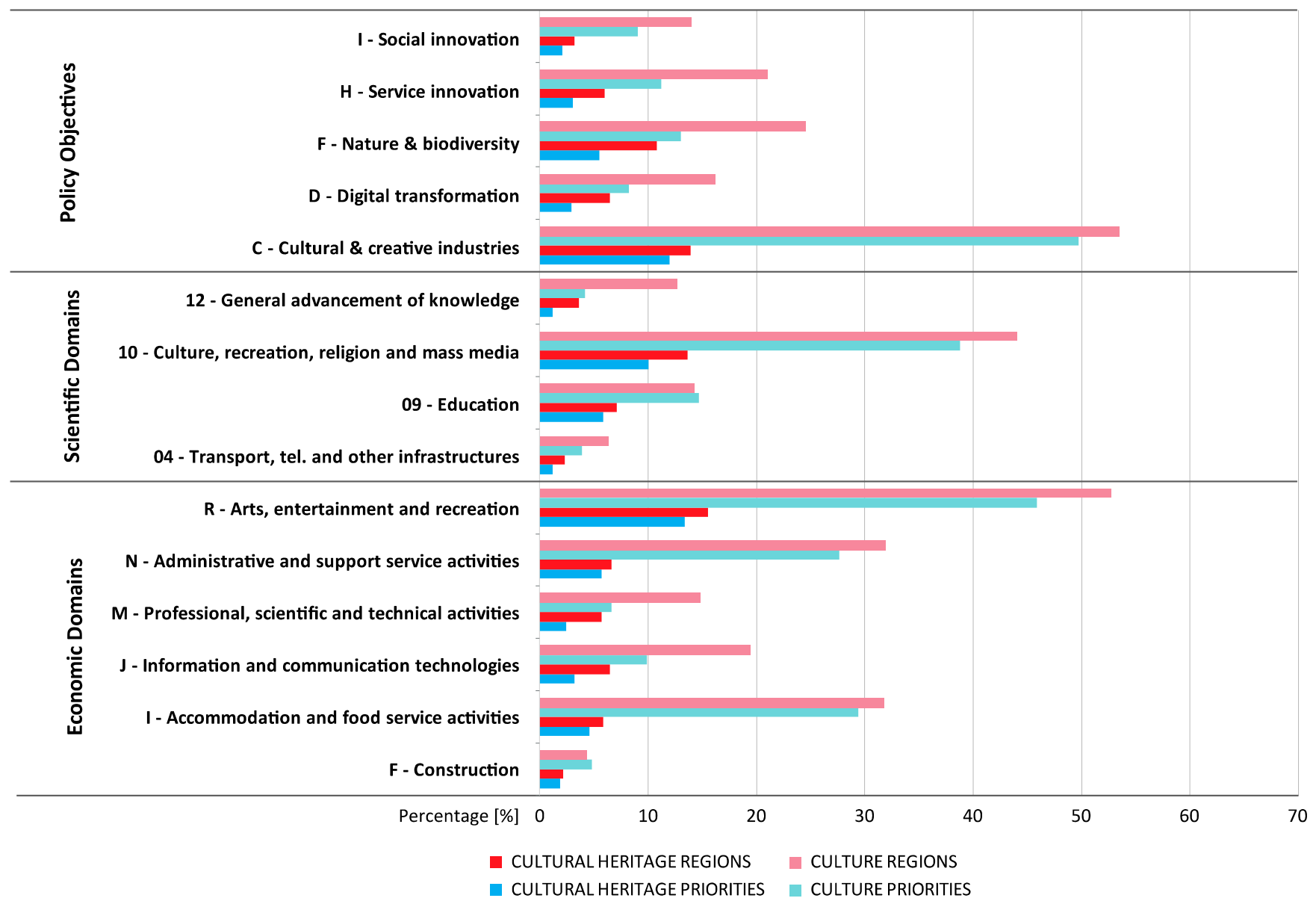

Figure 5. Percentage of regions and priorities having culture/cultural heritage as a focus in relation to main economic and scientific domains and policy objectives in proportion to related ones.

A notable difference exists when only a cultural heritage search has been performed, where the percentage drops to around $15 \%$. From the very similar three-fold drop in all three domains/objectives, we can assume that cultural heritage represents around $30 \%$ of the culture industry. Two other economic domains, $\mathrm{N}$-administrative and support service activities and I-accommodation and food service activities, show notably higher importance of wider search criteria with percentages around $30 \%$. This could be attributed to the direct connection of these domains with cultural activities that require physical presence and logistics, such as tourism. Other domains worth mentioning are: J-information and communication technologies, M-professional, scientific and technical activities, 12-general advancement of knowledge and 09-education, as well as policy objectives: $\mathrm{F}$-nature and biodiversity, $\mathrm{H}$-service innovation and I-social innovation, all falling between $15 \%$ and $25 \%$ when applying the wider concept of culture.

However, using restrictive cultural heritage search gives average percentages hardly going above $10 \%$, such as in the case of the first three domains mentioned. Average values across domains/objectives for cultural heritage can indicate that cultural heritage has not 
been adequately recognised in the other-than-primary domains. This is especially true for the domain F-construction, which has 5\% for wider and 2\% for restrictive search.

Such a low percentage can highlight how cultural heritage is under-evaluated in the construction market and its circularity capacity in the case of Europe (more detailed explanation in Figure 6, with all relevant sub-domains). Another visible aspect across all domains/objectives is a highly constant and proportional drop when comparing regions to priorities. This can be the result of a much higher number of priorities per region/city and priorities in total.

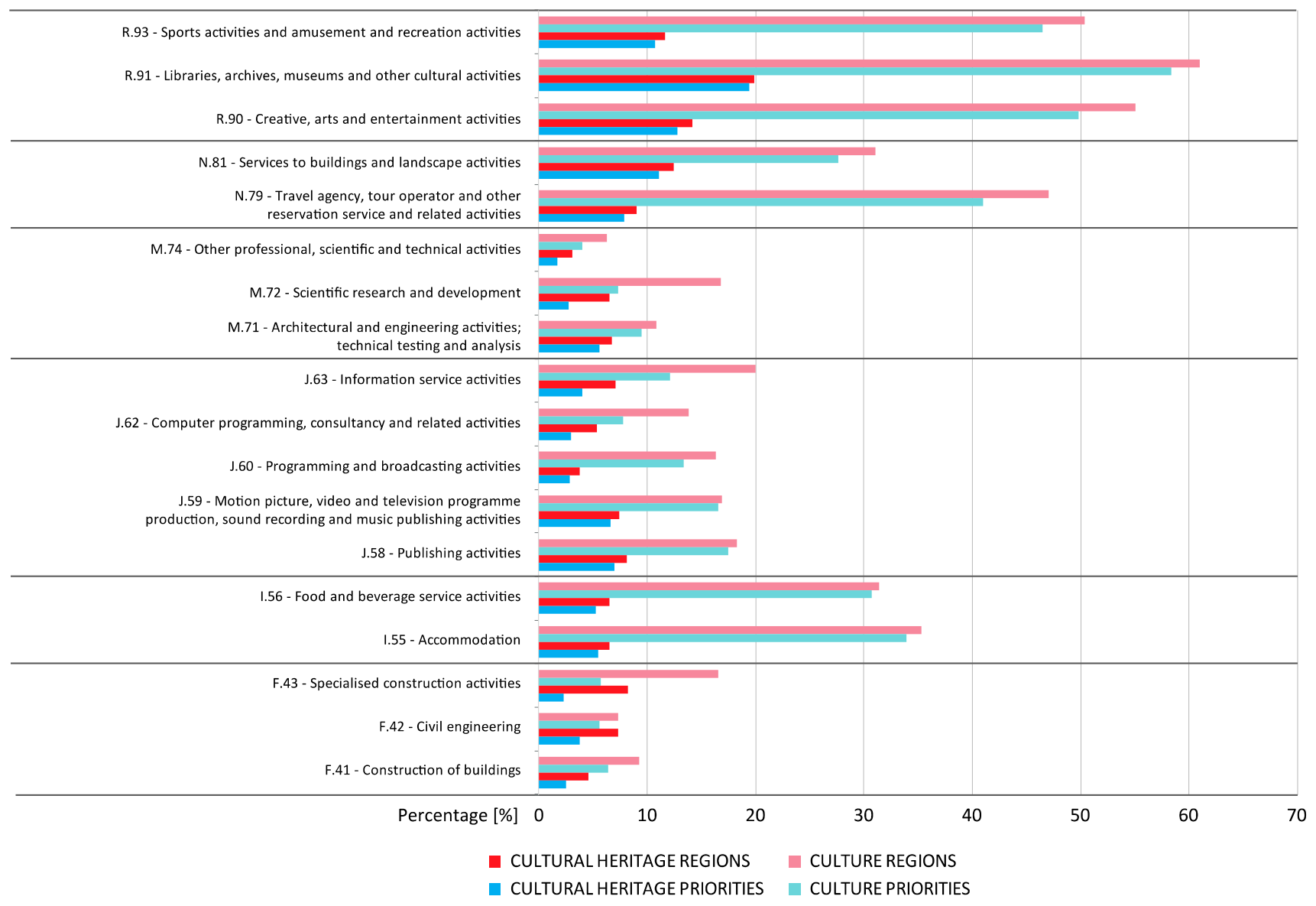

Figure 6. Percentage of regions and priorities having culture/cultural heritage as a focus in relation to main economic sub-domains in proportion to related ones.

Narrowing down the search from main domains to sub-domains, the same trends are visible. Figure 6 shows economic sub-domains of $\mathrm{R}, \mathrm{N}$ and I are significantly larger in percentages. Worth mentioning is a small peak in F.43-specialised construction activities only for wider culture and cultural heritage search that could mean that culture, in general, is more linked to specialised construction activities than cultural heritage, a notion that definitely shows an underestimation of cultural heritage and a relatively poor perception of its importance for circular economy.

Scientific sub-domains are presented in Figure 7. As already mentioned, sub-domains of 10-culture, recreation, religion and mass media show drastically dominant linkage to wider keywords, mainly above $40 \%$. On the other hand, when taking into account the restrictive search of cultural heritage only, they all drop to average levels of around $10 \%$. Scientific sub-domains of 04-transport, telecommunication and other infrastructures show very little connection to both search criteria. Educational sub-domains show a constant percentage around $20 \%$ and $10 \%$ for wide and strict search, respectively. 


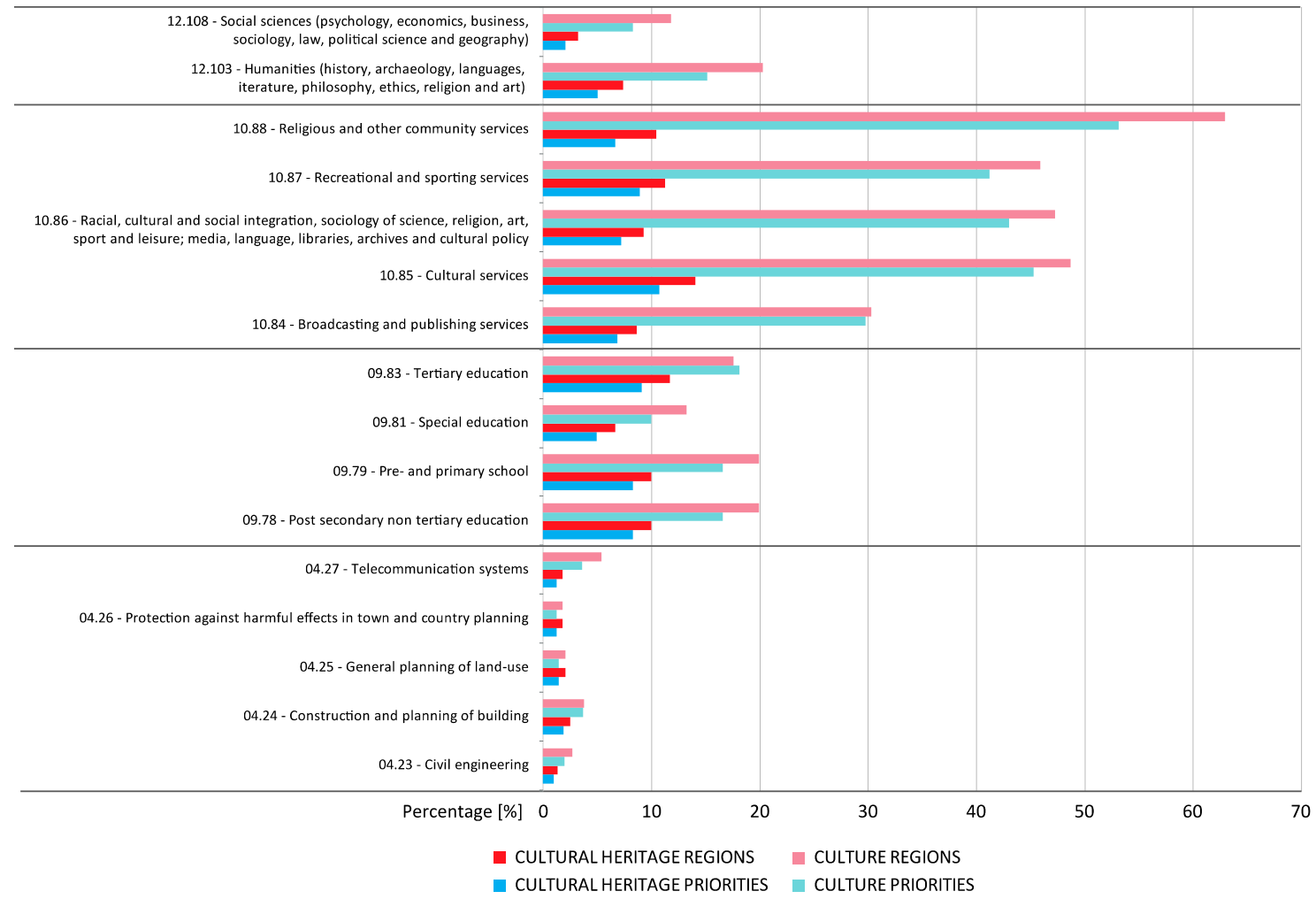

Figure 7. Percentage of regions and priorities having culture/cultural heritage as a focus in relation to main scientific sub-domains in proportion to related ones.

Results of the analysis for policy sub-objectives are shown in Figure 8. Similarly to the policy objectives already discussed, sub-objectives show two dominant linkages in Ccultural and creative industries and F-nature and biodiversity, when taking into account wider search. When considering cultural heritage only, percentages drop around four times and fall in the range of 10 to $20 \%$. The next important contribution, culture and cultural heritage, give to D.33-new media and easier access to cultural contents (e.g., heritage) and D.19-artificial intelligence, cognitive systems, augmented and virtual reality, visualisation, simulation, gamification and interaction technologies. Although heritage was explicitly mentioned, percentages for cultural heritage, comparing to wider culture search keyword, are only half of the latter one. Other sub-objectives in $\mathrm{H}$-service innovation and I-social innovation, all associated with a concept "new", are considerably less connected, especially in the case of cultural heritage search. This could imply that social and service innovations in the cultural heritage sector are perceived as less important than other sub-objectives for circular economy.

\subsection{Analysis 2 Results}

Analysis 2 aims to examine the presence and importance that cultural heritage and culture have on an overall economy, science and policies in relation to the total number of regions/cities and priorities. Results of the main three categories for related domains/objectives are shown in Figure 9. These 15 domains/objectives shown represent 36\% of the total of 41 domains/objectives. The rest of the domains/objectives are not presented, as their percentages (appearance of cultural heritage in any context) are equal to zero. When counting the number of regions/cities and priorities containing wider search (for both culture and cultural heritage), it is acquired that culture is mentioned in 80 regions/cities and 103 priorities that represent $33 \%$ and $7 \%$ of the total, respectively. Restricting search to only cultural heritage, the number of regions and priorities are falling to 24 and 26 , respectively. Their percentages are also falling to $10 \%$ and $2 \%$ of total regions/cities and priorities, respectively. 


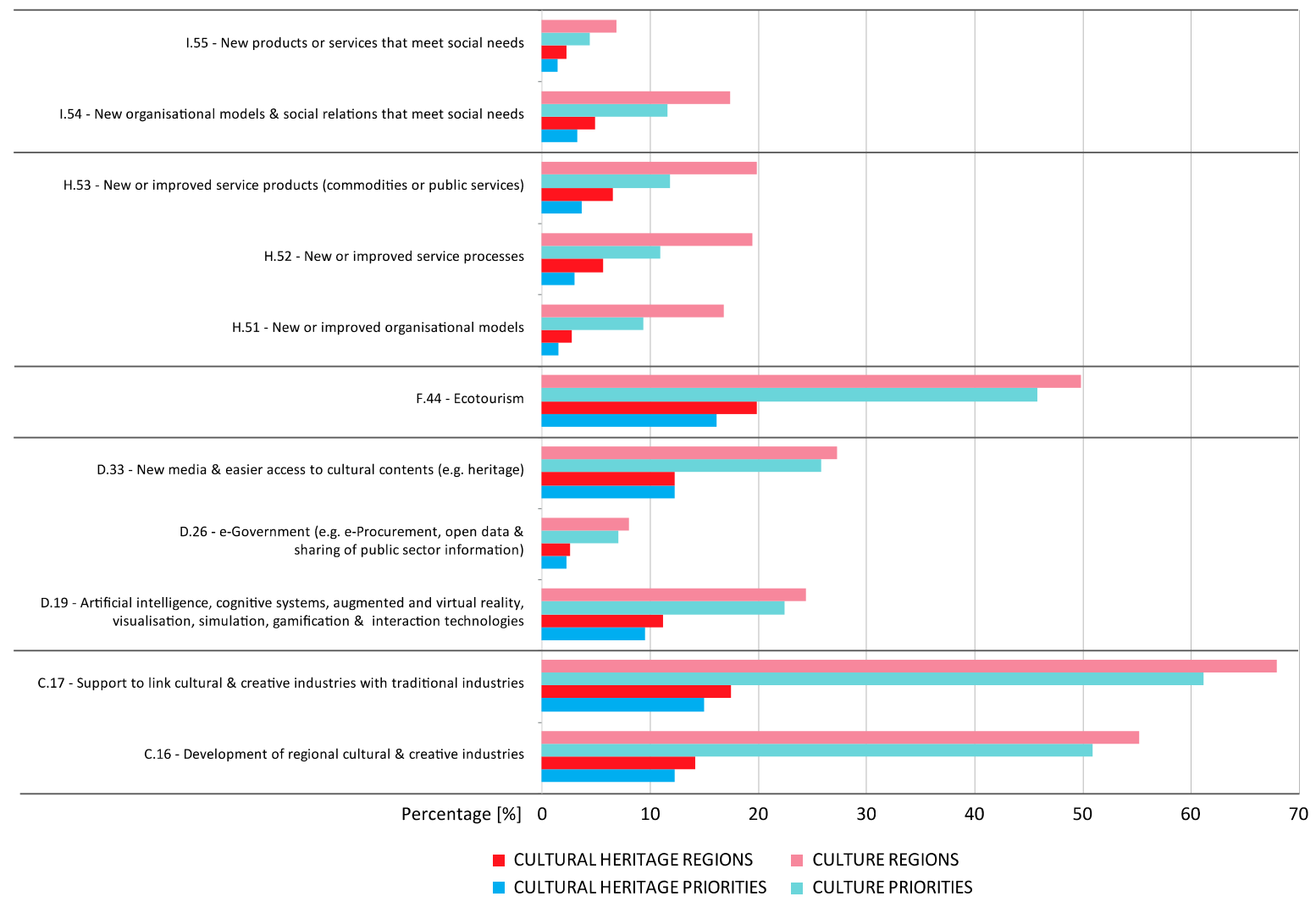

Figure 8. Percentage of regions and priorities having culture/cultural heritage as a focus in relation to main policy sub-objectives in proportion to related ones.

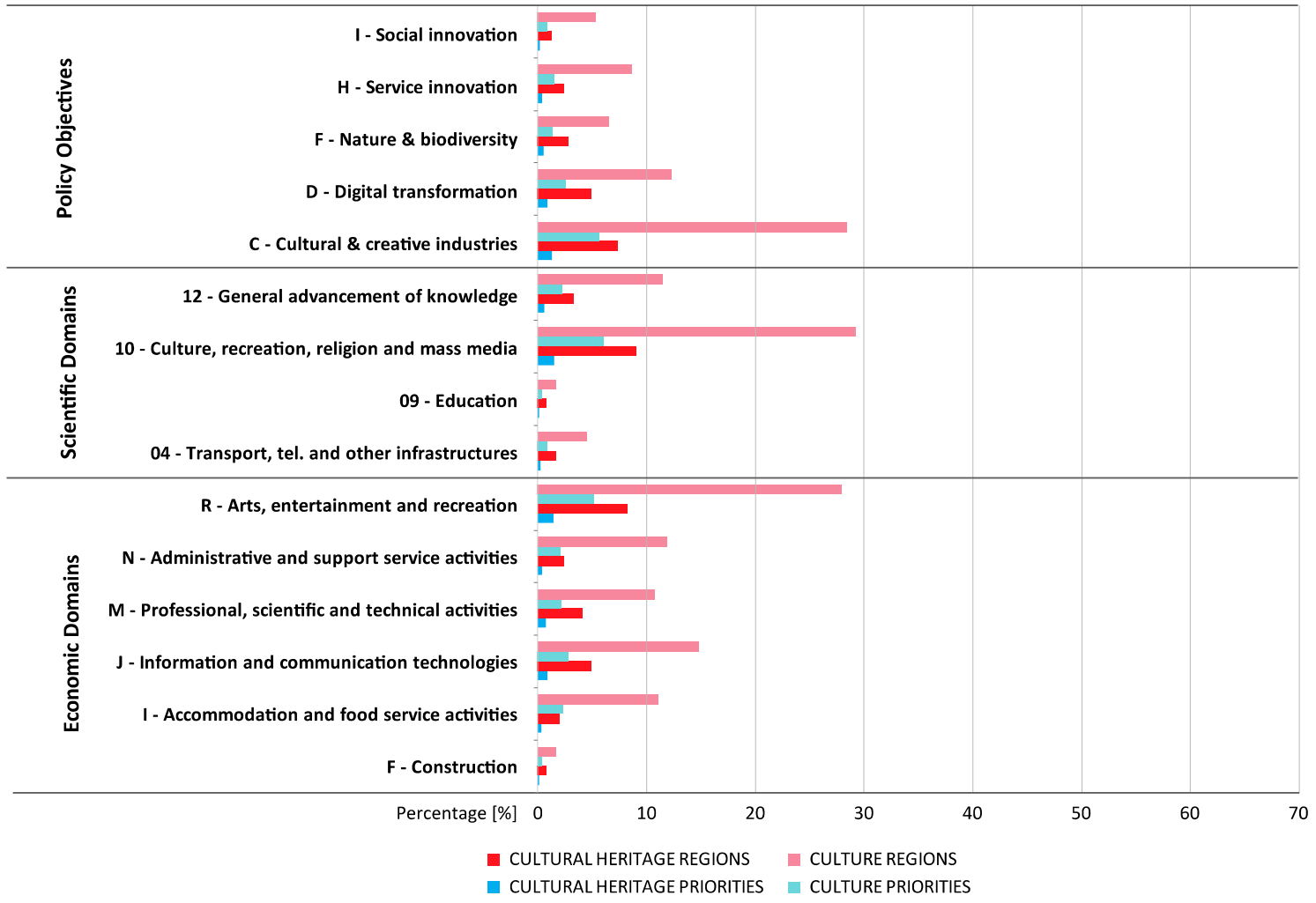

Figure 9. Percentage of regions and priorities having culture/cultural heritage as a focus in relation to main economic and scientific domains and policy objectives in proportion to the total number of regions and priorities. 
Since now the comparison is conducted on the total number of domains/objectives and on the total number of regions/cities and priorities, not only related ones with cultural heritage and culture (as explained, the ones in which "culture" and "cultural heritage" showed up as a priority for at least one region), a significant drop in percentages is recognisable and expected. Exceptions are similar in analysis 1, economic domain R-arts, entertainment and recreation, scientific domain 10-culture, recreation and mass media, as well as with policy objective C - cultural and creative industries. However, these peaks are applicable only for a wider search and when taking into account regional distribution. Nevertheless, the importance and overall distribution of percentage are in the range from $5 \%$ to $15 \%$ for culture and 3\% to $9 \%$ for cultural heritage on the regional level. While the construction sector may neglect cultural heritage inclusion and use for circular economy and evaluate it as barely a few percent, under-representation in the educational domain may indicate limited interests for culture and cultural heritage in education.

A total of 18 relevant economic sub-domains out of 82 in total are presented in Figure 10. As presented in the main categories, the largest share falls on culture in service industries and creative arts and entertainment activities, considering the regional level. Worth mentioning is a lack of differentiation between F.43 specialised construction activities and F.41 construction of buildings, while some difference in favour of the first one could have been expected. Although European regions are abandoning cultural heritage as a part of their construction sector, which we could also understand from different national and regional circular economy strategies [1], this indication is of relevance, especially because F.41, F.42 and F.43 fall in economic domains and shall play an important role in circular economy.

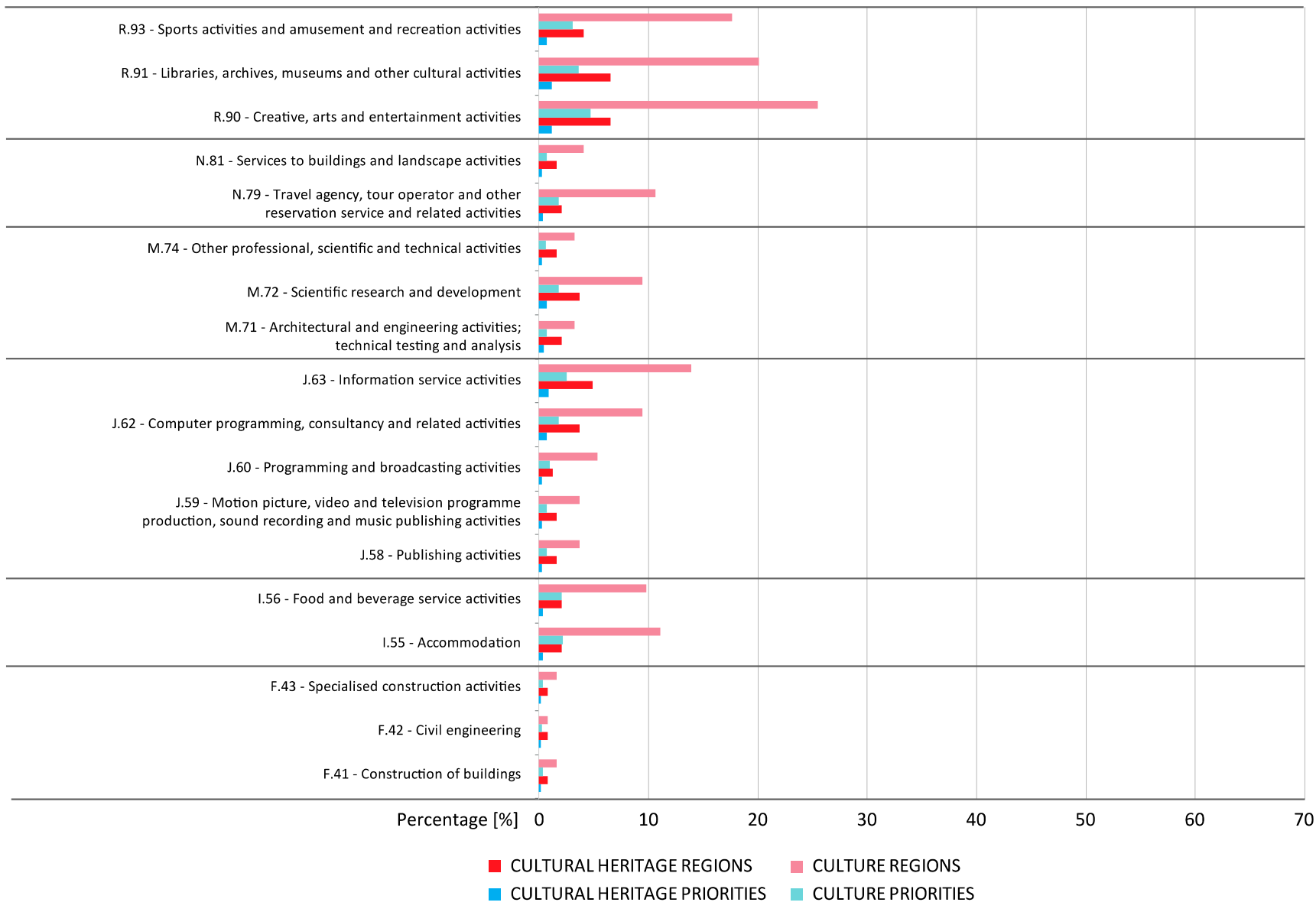

Figure 10. Percentage of regions and priorities having culture/cultural heritage as a focus in relation to main economic sub-domains in proportion to the total number of regions and priorities. 
Scientific sub-domains show greater variance and disproportion, presented in Figure 11. Out of 16 presented sub-domains, and 109 in total, only three have notable importance of around 20\%: 10.85-cultural services, 10.86-racial, cultural and social integration, sociology of science, religion, art, sport and leisure; media, language, libraries, archives and cultural policy and 10.87-recreational and sporting services. The rest of the sub-domains barely exceed a few per cent.

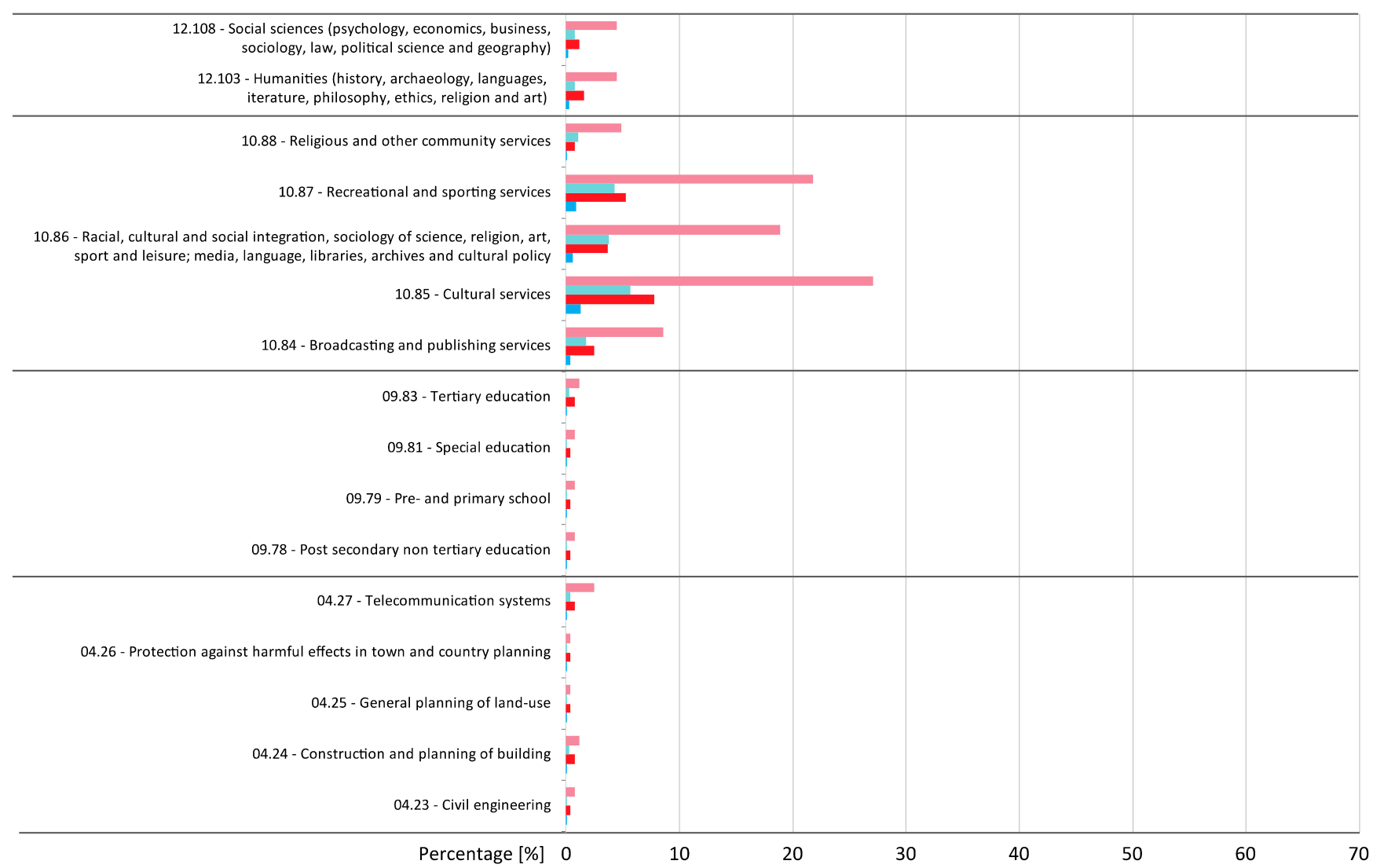

Figure 11. Percentage of regions and priorities having culture/cultural heritage as a focus in relation to main scientific sub-domains in proportion to the total number of regions and priorities.

Figure 12 shows 11 out of 72 policy sub-objectives, and again only a few of them show notable influence. In this case, policy objectives on cultural and creative industries only partially relate to the cultural heritage. D.33 new media and easier access to cultural contents (e.g., heritage) with less than $10 \%$ in all four parameters does not stand out as it might be expected. Again, new and improved products or services do not associate significantly with the cultural heritage, and that would need to be work out in finding ways how cultural heritage can benefit from innovative ideas for circular economy.

\subsection{Analysis 3 Results}

Analysis 3 aims at evaluating the impact that cultural heritage and culture have on each specific region/city toward circular economy. Results of wider search criteria are shown in Figure 13. A total of 80 regions are colour-coded according to the percentage of priorities that included a search for each specific region. In those terms, percentages of 50\% and more represent regions where culture and cultural heritage are extremely important, being among top priorities for that region. Regions like ITH3 Veneto and Greece have one of the highest percentages. They are followed by regions in Portugal, Spain, north-west France, Central Europe and very north regions in some Scandinavian regions. Overall distribution may seem loose. However, the trend of the increased importance of culture and cultural heritage may be associated with industrially less developed regions. For example, 
regions with the presence of industry and strong correlation with circular economy in general, as well as cultural heritage like ones in the Netherland, Germany, France and especially the UK, do not even mention culture or cultural heritage and, therefore, are completely under-represented. On the other hand, less industrialised regions with unique old city centres recognised as UNESCO world heritage sites like La Valetta in Malta do not recognise how profoundly cultural heritage contributes to society, directly and through spill-over effects. Norwegian regions rank culture high in their priorities for circular economy.

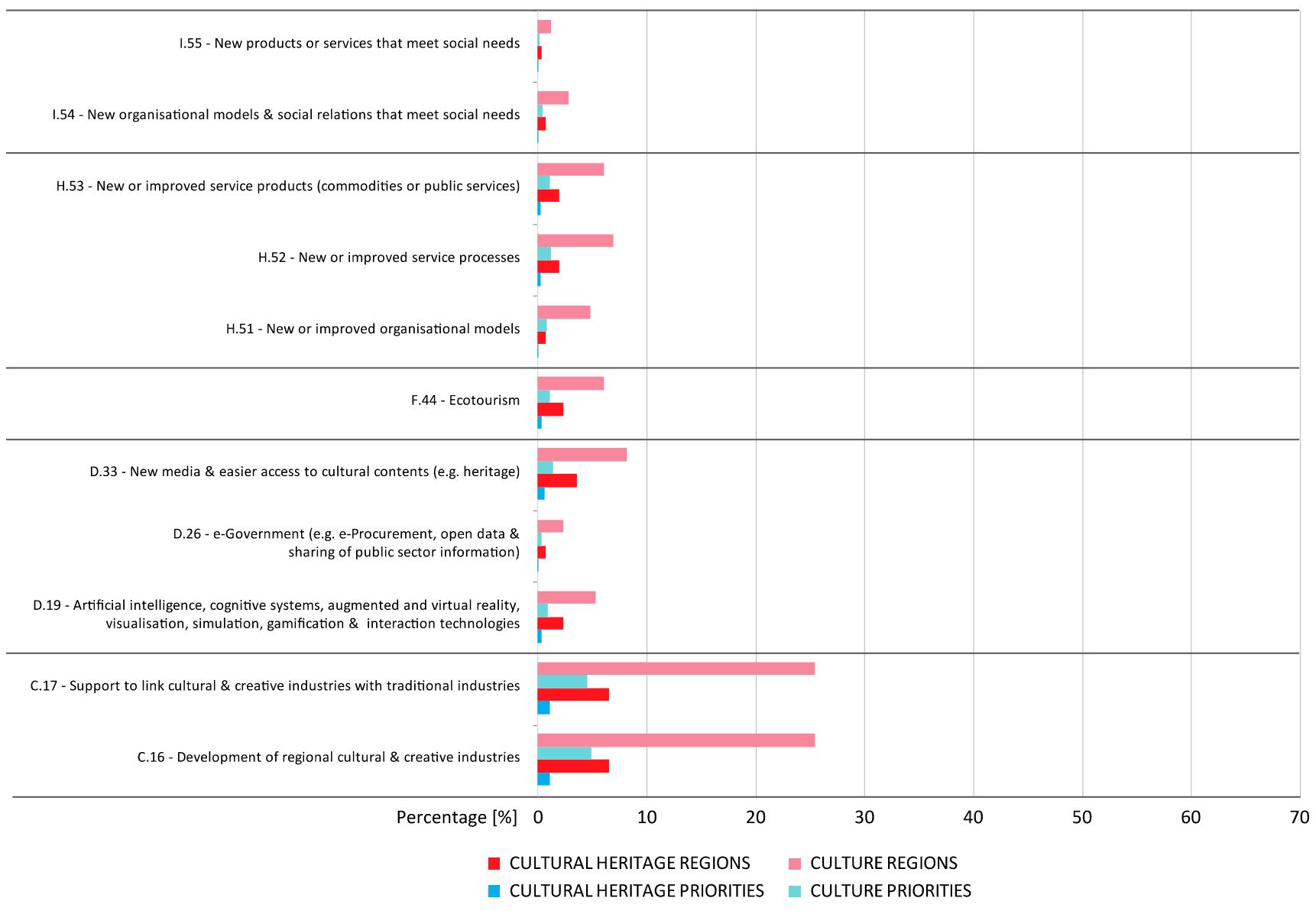

Figure 12. Percentage of regions and priorities having culture/cultural heritage as a focus in relation to main policy sub-objectives in proportion to the total number of regions and priorities.

When reducing search only to cultural heritage, the number of regions drops to 24 . Those regions are mostly in southern Europe, with the exceptions of the BE2 Flemish region and PL61 Kujawsko-Pomorskie-Figure 14. Scandinavian regions, together with the UK, France and Germany, have no region that specifically mentions cultural heritage. In those terms, regions such as Lazio would probably need to put higher recognition on their heritage. Surprisingly, regions such as Tuscany falls short in recognising cultural heritage as one of society driving forces. 


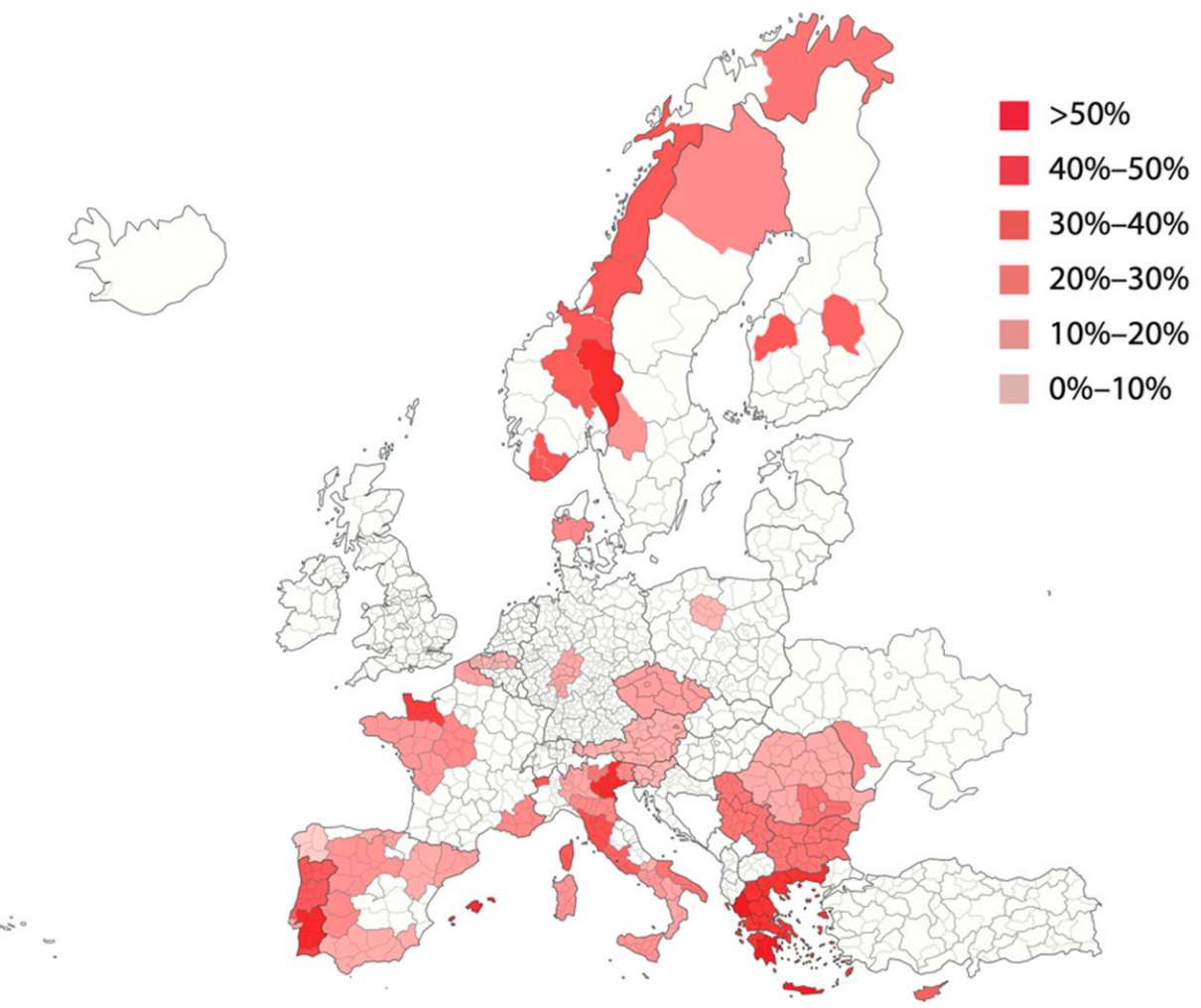

Figure 13. Graphical presentation of regions prioritising culture and cultural heritage with colour-coding.

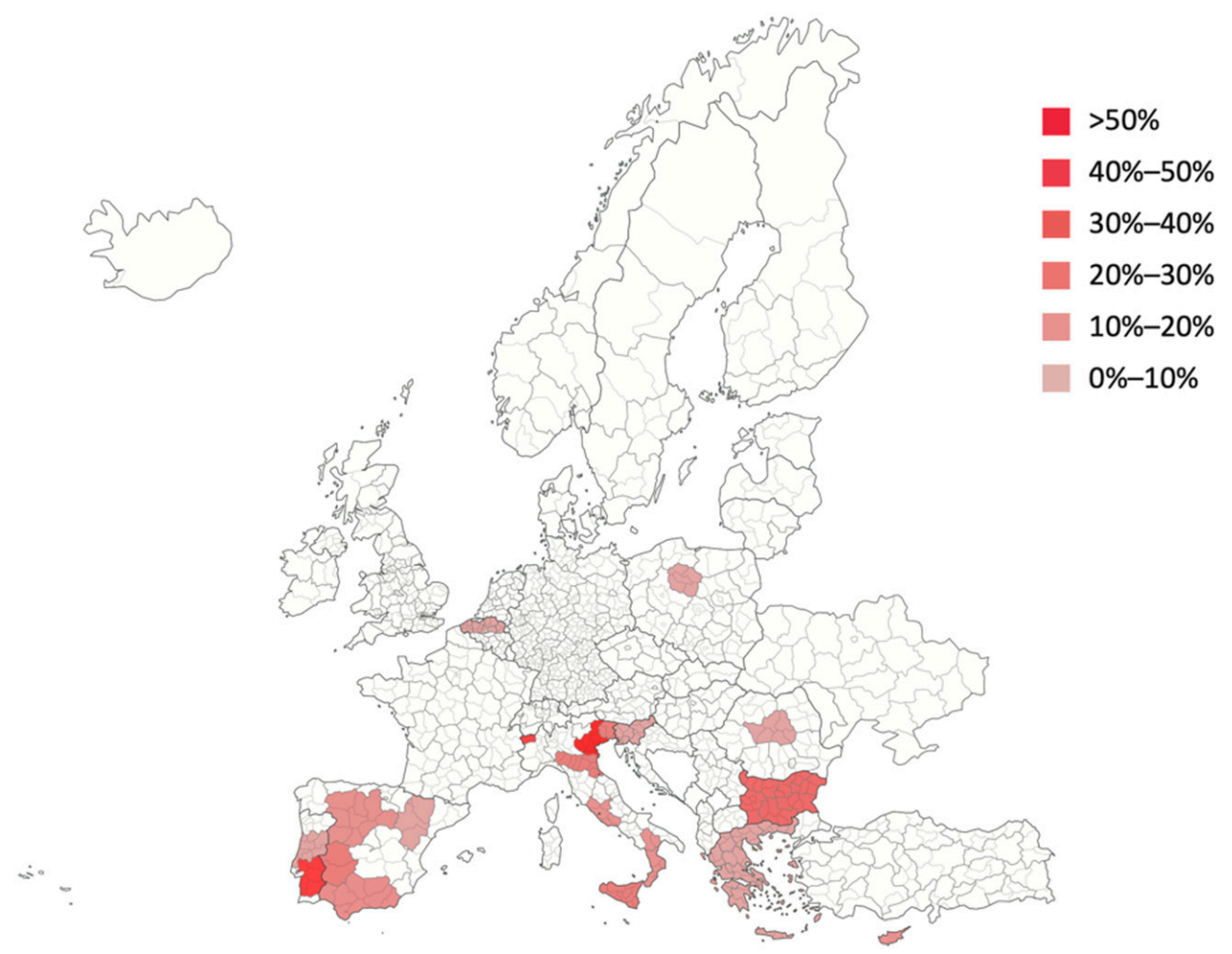

Figure 14. Graphical presentation of regions prioritising cultural heritage with colour-coding. 


\section{Discussion}

Overall, as mentioned in the literature review, the lack of research on this topic is evident. The initial objective of the research was to overcome a gap in the data reviews regarding this topic and provide the most extensive list of cultural heritage oriented regions and their features across cultural heritage and circularity. Therefore, it is now feasible to declare that a very low number of NUTS (regions/cities) include cultural heritage through smart specialisation in their regional strategies for circular economy. This research sets out the baseline and the most recent understanding in regard to the current situation at the NUTS (regional/city) levels. Outcomes from the analysis indicate the following: some NUTS entities have included culture, cultural heritage and circular economy in their regional innovation strategies for smart specialisation individually, consequently defining circular economy as a priority sector for the region, but still not incorporating culture, cultural heritage and adaptive reuse as a part of its deployment.

Another major finding is that the cultural heritage is under-evaluated in the construction market as well as its circularity capacity, which is readable from the respective economic domain, Construction and its respective sub-domains. It is interesting to note that cultural heritage is not adequately recognised as a potential for economic development under the economic domain associated with adaptive reuse and circular economy. The results of the research did not show coherence in using adaptive reuse in relation to cultural heritage. It has not been mainstreamed in circular economy strategies or in smart specialisation strategies.

It was not surprising that culture and cultural heritage are mainly appearing in domains/sub-domains and objectives/sub-categories obviously related to culture, such as art, entertainment and recreation for economic domains and their respective sub-domains, or culture, recreation, religion and mass media for scientific domains and their respective sub-domains, as well as cultural and creative industries when it comes to policy objectives, which at the same time shows the most significant cultural heritage and culture features and workflows that are currently available in different European regions toward circularity processes.

In addition to that, cultural and creative regional ecosystems (CCRE-S3) thematic area has been set at S3, together with other thematic areas (e.g., bio-economy, chemicals, cybersecurity etc.). However, mainstreaming culture and cultural heritage in smart specialisations strategies still needs to evolve through non-related priorities as well as cultural and creative regional ecosystems. One of the CCRE-S3 aims is to foster a multi-stakeholder dialogue in order to unify perspectives s for new models of CCI based on the human-centred design of user experiences, circular economy creativeness and city/territory regeneration, and open and collaborative innovation paradigms. This research confirms the lack of multi-stakeholder dialogue.

The results of this study indicate that besides many invitations from different sectors for a multi-dimensional approach to circular economy, cultural heritage still has not reached its adequate position, and the innovation potential of cultural heritage still remains far from being properly achieved [44] in circular economy; in particular, when it comes to strategic aspects. The findings of all analysis are consistent, and these findings support that there is a lack of previous research on this topic. A possible explanation for these results may be the lack of adequate transformation agenda for cultural heritage as the smart specialisations within circular economy are transformative in themselves.

Although different literature reviews and projects are confirming the hypothesis that regions and cities started playing an important role in the heritage field, they recognisably fail in terms of smart specialisations and circular economy policymaking, management and regulation, which could lead us to the second possible explanation of the results—cultural heritage stakeholders are not involved in these processes. This research has been unable to demonstrate that but an assumption can be developed based on data interpretation. It can be thus suggested that encouraging and empowering cities' and regions' actors to a better 
position within smart specialisations and circular economy processes would most likely position cultural heritage in a more pertinent way to these respective policies.

This is an important issue for future research and, therefore, it may be the case that these variations and more interactions among different stakeholders could better position cultural heritage. Further work is required to explore this. It is not enough anymore to explore the involvement of different stakeholders in cultural heritage processes, but involvement and engagement of cultural heritage actors in other fields such as circular economy, climate changes, innovation, etc. Further studies, which take these variables into account, reflected into smart specialisations, will need to be undertaken.

\section{Conclusions}

Nonetheless, the research shows that the designation and representation of cultural heritage and culture in the existing smart specialisation approach as a tool to strengthen innovation for the circular economy is very low. These results, with accurate and very detailed percentages, are not very encouraging but shall offer implications and a starting point for further developing improvements at both academic research and policy levels and act as a benchmark for further growths.

Thematic area platforms, such as cultural and creative regional ecosystems (CCRE-S3), could be seen as a tool to engage more regions than that are involved currently, but this study has shown that this process has to be done in a more strategic way rather than on an ad hoc projects' basis.

Although creative and cultural sectors are a significant growth factor in numerous regions and cities, incorporation of these features into circular economy domains and smart specialisation strategies broadly remains a challenge that local, regional, national and supranational governments will have to address. The complexity of interconnections between the traditional cultural assets, such as cultural heritage adaptive reuse and domains that have appeared in analyses expectedly, on the one hand, and the improvement of circular economy and different non-cultural-heritage concepts, on the other, regions and cities will need to recognise, take into account and work further on their strategic and systemic integration.

This research understands current and further possible advancements on the topic of cultural heritage and culture in smart specialisations as it clearly shows discrepancies in results among priorities and regions. Findings could be portrayed as a supplement to considerations on establishing a proposal of the areas and pillars to be subjects of analysis in tracking the implementation of circular economy. Earlier studies underlined that cultural aspects play an important role in determining the evolution towards more sustainable alternatives and the embracing and adopting of circular economy principles. This is an important issue for future research, as there is abundant room for further progress in determining social and cultural aspects of methodological issues and technological aspects of circular economy.

Further research, which takes these elements into account, will need to be undertaken, but mainly together with research and evidence-based oriented improvements of regional strategic documents in regard to cultural heritage and smart specialisations, as regions simply fail to do that so far. Therefore, in addition to the primary challenges in regard to these interrogations, the technical issues and the technological aspects of the circular economy, determined attempts need to be made in fostering communication, understanding and information exchange concerning the social and cultural features that have not been explored enough.

Author Contributions: The authors have contributed equally to the development of this research paper. All authors have read and agreed to the published version of the manuscript.

Funding: This research was funded under the framework of Horizon 2020 research project CLIC: Circular models Leveraging Investments in Cultural heritage adaptive reuse. This project has received 
funding from the European Union's Horizon 2020 research and innovation program under Grant Agreement No. 776758.

Institutional Review Board Statement: Not applicable.

Informed Consent Statement: Not applicable.

Data Availability Statement: The dataset is available upon request.

Conflicts of Interest: The authors declare no conflict of interest. The funders had no role in the design of the study, in the collection, analyses, or interpretation of data, in the writing of the manuscript, or in the decision to publish the results.

\section{References}

1. Stanojev, J.; Gustafsson, C. Circular Economy Concepts for Cultural Heritage Adaptive Reuse Implemented Through Smart Specialisation Strategies. Proc. Sts Conf. Graz 2019. [CrossRef]

2. Fusco Girard, L.; Nocca, F. Moving towards the circular economy/city model: Which tools for operationalising this model? Sustainability 2019, 11, 6253. [CrossRef]

3. European Commission. Communication from the Commission to the European Parliament, The Council, The European Economic and Social Committee and the Committee of the Regions Closing the Loop - An EU Action Plan for The Circular Economy; European Commission: Brussels, Belgium, 2015.

4. Kirchherr, J.; Reike, D.; Hekkert, M. Conceptualising the circular economy: An analysis of 114definitions. Resour. Conserv. Recycl. 2017, 127, 221-232. [CrossRef]

5. Geissdoerfer, M.; Savaget, P.; Bocken, N.; Hultik, E.J. The Circular Economy-A new sustainability paradigm? J. Clean. Prod. 2017, 143, 757-768. [CrossRef]

6. Smol, M.; Kulczycka, J.; Avdiushchenko, A. Circular economy indicators in relation to eco- innovation in European regions. Clean Technol. Environ. Policy 2017, 19, 669-678. [CrossRef]

7. Korhonen, J.; Nuur, C.; Feldmann, A.; Eshetu Birkie, S. Circular economy as an essentially contested concept. J. Clean. Prod. 2018, 175, 544-552. [CrossRef]

8. Reike, D.; Vermeulen, W.J.V.; Witjes, S. The circular economy: New or refurbished as CE 3.0?-Exploring controversies in the conceptualisationconceptualization of the circular economy through a focus on history and resource value retention options. Resour. Conserv. Recycl. 2018, 135, 246-264. [CrossRef]

9. Prieto-Sandoval, V.; Jaca, C.; Ormazabal, M. Towards a consensus on the circular economy. J. Clean. Prod. 2018, 179, 605-615. [CrossRef]

10. Gladek, E. The Seven Pillars of the Circular Economy. 2017. Available online: http://www.metabolic.nl/the-seven-pillars-of-thecircular-economy/ (accessed on 15 August 2019).

11. de Vries, B.J.M.; Petersen, A.C. Conceptualizing sustainable development: An assessment methodology connecting values, knowledge, worldviews and scenarios. Ecol. Econ. 2009, 68, 1006-1019. [CrossRef]

12. Lieder, M.; Rashid, A. Towards circular economy implementation: A comprehensive review in context of manufacturing industry. J. Clean. Prod. 2016, 115, 36-51. [CrossRef]

13. Yuan, Z.; Bi, J.; Moriguichi, Y. The circular economy: A new development strategy in China. J. Ind. Ecol. 2006, 10, 4-8. [CrossRef]

14. Murray, A.; Skene, K.; Haynes, K. The circular economy: An interdisciplinary exploration of the concept and application in a global context. J. Bus. Ethics 2017, 140, 369-380. [CrossRef]

15. Ellen MacArthur Foundation. Towards the Circular Economy: Accelerating the Scale-up Across Global Supply Chains. 2014. Available online: http://www3.weforum.org/docs/WEF_ENV_TowardsCircularEconomy_Report_2014.pdf (accessed on 31 January 2014).

16. UNEP. Towards a Green Economy: Pathways to Sustainable Development and Poverty Eradication; UNEP: Nairobi, Kenya, 2011.

17. OECD. Farm Management Practices to Foster Green Growth. 2016. Available online: https://www.oecd.org/publications/farmmanagement-practices-to-foster-green-growth-9789264238657-en.htm (accessed on 23 February 2016).

18. Avdiushchenko, A. Toward a Circular Economy Regional Monitoring Framework for European Regions: Conceptual Approach. Sustainability 2018, 10, 4398. [CrossRef]

19. McDowall, W.; Geng, Y.; Huang, B.; Barteková, E.; Bleischwitz, R.; Türkeli, S.; Kemp, R.; Doménech, T. Circular economy policies in China and Europe. J. Ind. Ecol. 2017, 21, 651-661. [CrossRef]

20. Ranta, V.; Aarikka-Stenroos, L.; Ritala, P.; Mäkinen, S.J. Exploring institutional drivers and barriers of the circular economy: A cross-regional comparison of China, the US, and Europe. Resour. Conserv. Recycl. 2018, 135, 70-82. [CrossRef]

21. European Commission. Strengthening Innovation in Europe's Regions: Strategies for Resilient, Inclusive and Sustainable Growth (Doc. 11426/17 + ADD 1); European Commission: Brussels, Belgium, 2017.

22. European Commission, Joint Research Centre. Mapping Innovation Priorities and Specialisation patterns in Europe; European Commission: Seville, Spain, 2015.

23. European Commission. A New Circular Economy Action Plan For a Cleaner and More Competitive Europe (COM (2020) 98 Final); European Commission: Brussels, Belgium, 2020. 
24. European Commission. The European Green Deal (COM (2019) 640 Final); European Commission: Brussels, Belgium, 2019.

25. Gustafsson, C. CONSERVATION 3.0-Cultural Heritage as a driver for regional growth. Scires-It-Sci. Res. Inf. Technol. 2019, 9 , 21-32.

26. Rivas, M.; Cappellano, F. Linking Cultural Heritage to Smart Specialisation Strategies. ROCK Project-Regeneration and Optimisation of Cultural Heritage in Creative and Knowledge Cities; H2020-SC5-2016-2017 GA 730280; 2020; Available online: file:/ / / : /Users / MDPI/AppData/Local/Temp/linking-cultural-heritage-to-smart-specialisation-strategies-1.pdf (accessed on 19 March 2021).

27. Boschma, R. Constructing regional advantage and smart specialisation: Comparison of two European policy concepts. Sci. Reg. Ital. J. Reg. Sci. 2014, 13, 51-68. [CrossRef]

28. Capello, R. Smart specialisation strategy and the EU policy reform: Introductory remarks. Sci. Reg. Ital. J. Reg. Sci. 2014, 13, 5-14

29. Capello, R.; Kroll, H. From theory to practice in smart specialisation strategy: Emerging limits and possible future trajectories. Eur. Plan. Stud. 2016, 24, 1393-1406. [CrossRef]

30. Kroll, H. Efforts to implement smart specialisation in practice-Leading unlike horses to the water. Eur. Plan. Stud. 2015, 23, 2079-2098. [CrossRef]

31. Kroll, H.; Dornbusch, F.; Schnabl, E. Universities' regional involvement in Germany: How academics' objectives and opportunity shape choices of activity. Reg. Stud. 2015, 50, 1595-1610. [CrossRef]

32. McCann, P.; Ortega-Argilés, R. Smart specialisation, regional growth and applications to European Union cohesion policy. Reg. Stud. 2015, 49, 1291-1302. [CrossRef]

33. McCann, P. The Regional and Urban Policy of the European Union: Cohesion, Results-Orientation and Smart Specialisation; Edward Elgar Publishing: Milano, Italy, 1987.

34. Coffano, M.; Foray, D. The centrality of entrepreneurial discovery in building and implementing a smart specialisation strategy, Scienze Regionali. Ital. J. Reg. Sci. 2014, 13, 33-50.

35. Foray, D. Smart Specialisation: Opportunities and Challenges for Regional Innovation Policy; Routledge: Abingdon, UK, 2015.

36. Foray, D. On the policy space of smart specialisation strategies. Eur. Plan. Stud. 2016, 24, 1428-1437. [CrossRef]

37. Ost, C. Inclusive Economic Development in the Urban Heritage Context. In World Heritage and Sustainable Development; New Directions in World Heritage Management; Larsen, P.B., Longa, W., Eds.; Routledge: Oxon, UK; New York, NY, USA, 2018; pp. 53-67.

38. Fusco Girard, L. The role of cultural urban landscape towards a new urban economics: New structural assets for increasing economic productivity through hybrid processes. Hous. Policies Urban Econ. 2014, 1, 3-27.

39. Ripp, M.; Lukat, A.H. From Obstacle to Resource: How Built Cultural Heritage Can Contribute to Resilient Cities; Springer: Cham, Switzerland, 2017; pp. 99-112.

40. Janssen, J.; Luiten, R.; Renes, H.; Stegmeijer, E. Heritage as a sector, factor and vector: Conceptualising the shifting relationship between management and spatial planning. Eur. Plan. Stud. 2017, 25, 1654-1672. [CrossRef]

41. Stanojev, J. Progression Analytics and Establishing Continuum of Participatory Governance in Cultural Heritage. Scires-It-Sci. Res. Inf. Technol. 2019, 9, 79-90.

42. Fatorić, S.; Biesbroek, R. Adapting cultural heritage to climate change impacts in the Netherlands: Barriers, interdependencies, and strategies for overcoming them. Clim. Chang. 2020, 162, 301-320. [CrossRef]

43. Foster, G. Circular economy strategies for adaptive reuse of cultural heritage buildings to reduce environmental impacts Resour. Conserv. Recycl. 2020, 152, 104507. [CrossRef]

44. Sonkoly, G.; Vahtikari, T. Innovation in Cultural Heritage: For an Integrated European Research Policy; Working Paper; European Commission, Publications Office: Luxembourg, 2018. 